\title{
Renal manifestations of primary mitochondrial disorders (Review)
}

\author{
JOSEF FINSTERER $^{1^{*}}$ and FULVIO SCORZA ${ }^{2 *}$ \\ ${ }^{1}$ Neurological Department, Municipal Hospital Rudolfstiftung, A-1030 Vienna, Austria; \\ ${ }^{2}$ Paulista de Medicina School, Federal University of São Paulo, Primeiro Andar CEP, São Paulo 04039-032, SP, Brazil
}

Received February 8, 2017; Accepted March 31, 2017

DOI: $10.3892 / b r .2017 .892$

\begin{abstract}
The aim of the present review was to summarize and discuss previous findings concerning renal manifestations of primary mitochondrial disorders (MIDs). A literature review was performed using frequently used databases. The study identified that primary MIDs frequently present as mitochondrial multiorgan disorder syndrome (MIMODS) at onset or in the later course of the MID. Occasionally, the kidneys are affected in MIDs. Renal manifestations of MIDs include renal insufficiency, nephrolithiasis, nephrotic syndrome, renal cysts, renal tubular acidosis, Bartter-like syndrome, Fanconi syndrome, focal segmental glomerulosclerosis, tubulointerstitial nephritis, nephrocalcinosis, and benign or malign neoplasms. Among the syndromic MIDs, renal involvement has been most frequently reported in patients with mitochondrial encephalomyopathy, lactic acidosis, and stroke-like episodes syndrome, Kearns-Sayre syndrome, Leigh syndrome and mitochondrial depletion syndromes. Only in single cases was renal involvement also reported in chronic progressive external ophthalmoplegia, Pearson syndrome, Leber's
\end{abstract}

Correspondence to: Dr Josef Finsterer, Neurological Department, Municipal Hospital Rudolfstiftung, Postfach 20, A-1030 Vienna, Austria

E-mail: fifigs1@yahoo.de

*Contributed equally

Abbreviations: CPEO, chronic progressive external ophthalmoplegia; FSGS, focal segmental glomerulosclerosis; GRACILE, growth retardation, aminoaciduria, cholestasis, iron overload, lactacidosis, and early death; GSECs, granular swollen epithelial cells; HUPRA, hyperuricemia, pulmonary hypertension, renal failure in infancy and alkalosis; KSS, Kearns-Sayre syndrome; LHON, Leber's hereditary optic neuropath; MDS, mitochondrial depletion syndrome; MELAS, mitochondrial encephalomyopathy, lactic acidosis, and stroke-like episodes; MERRF, myoclonus epilepsy with ragged-red fibers; MID, mitochondrial disorder; MIMODS, mitochondrial multi-organ disorder syndrome; MLASA, myopathy, lactic acidosis, and sideroblastic anemia; mtDNA, mitochondrial deoxyribonucleic acid; RTA, renal tubular acidosis; TDFS, Toni-Debré-Fanconi syndrome; TIN, tubulointerstitial nephritis; XLSA, X-linked sideroblastic anemia

Key words: mtDNA mutation, oxidative phosphorylation, renal dysfunction, renal tubular acidosis, respiratory chain hereditary optic neuropathy, coenzyme-Q deficiency, X-linked sideroblastic anemia and ataxia, myopathy, lactic acidosis, and sideroblastic anemia, pyruvate dehydrogenase deficiency, growth retardation, aminoaciduria, cholestasis, iron overload, lactacidosis, and early death, and hyperuricemia, pulmonary hypertension, renal failure in infancy and alkalosis syndrome. The present study proposes that the frequency of renal involvement in MIDs is probably underestimated. Diagnosis of renal involvement follows general guidelines and treatment is symptomatic. Thus, renal manifestations of primary MIDs require recognition and appropriate management, as they determine the outcome of MID patients.

\section{Contents \\ 1. Introduction \\ 2. Methods \\ 3. Results \\ 4. Conclusions}

\section{Introduction}

Depending on the phenotype, mitochondrial disorders (MIDs) are categorised as syndromic or non-syndromic (1). Syndromic MIDs are characterised by recurrent patterns of symptoms and signs, which have the same cause. Many of the syndromic MIDs are known by their acronyms (Table I), although there are a number of syndromic MIDs that have no acronym yet. A characteristic of syndromic MIDs is that they do not affect a single tissue or organ, but involve multiple tissues or organs (2). Multiorgan involvement in MIDs [mitochondrial multiorgan disorder syndrome (MIMODS)] (3) may already be present at onset of the clinical manifestations or may develop during the course of the disease. It appears that MIMODSs evolve as the duration of survival of the patient lengthens. The organs most frequently involved in MIDs are the skeletal muscles, peripheral nerves, central nervous system, eyes, ears, endocrine organs, heart, lungs, gastrointestinal tract, kidneys, bones (including the bone marrow) and the skin. The kidneys are known to be significantly involved in MIDs (4-7), although, to the best of our knowledge, a current, comprehensive and systemic review regarding kidney disease in MIDs is lacking. Transmission of a MID may follow any type of inheritance. The present review aims to summarise and discuss recent 
Table I. Renal disease in syndromic MIDs and nsMIDs.

\begin{tabular}{|c|c|c|c|c|c|c|c|c|c|c|}
\hline MID & $\mathrm{RF}$ & NL & NS & $\mathrm{RC}$ & RTA & BLS & TDFS & FSGS & TIN & $\mathrm{NC}$ \\
\hline MELAS & Yes & $\mathrm{N}$ & $\mathrm{N}$ & $\mathrm{N}$ & $\mathrm{N}$ & $\mathrm{N}$ & $\mathrm{N}$ & Yes & $\mathrm{N}$ & $\mathrm{N}$ \\
\hline KSS & Yes & $\mathrm{N}$ & $\mathrm{N}$ & $\mathrm{N}$ & Yes & Yes & Yes & $\mathrm{N}$ & $\mathrm{N}$ & Yes \\
\hline MDS & $\mathrm{N}$ & $\mathrm{N}$ & $\mathrm{N}$ & $\mathrm{N}$ & Yes & $\mathrm{N}$ & $\mathrm{N}$ & $\mathrm{N}$ & $\mathrm{N}$ & Yes \\
\hline LS & $\mathrm{N}$ & $\mathrm{N}$ & $\mathrm{N}$ & Yes & Yes & $\mathrm{N}$ & $\mathrm{N}$ & $\mathrm{N}$ & Yes & $\mathrm{N}$ \\
\hline CPEO & Yes & $\mathrm{N}$ & $\mathrm{N}$ & $\mathrm{N}$ & $\mathrm{N}$ & $\mathrm{N}$ & $\mathrm{N}$ & $\mathrm{N}$ & $\mathrm{N}$ & $\mathrm{N}$ \\
\hline PS & $\mathrm{N}$ & $\mathrm{N}$ & $\mathrm{N}$ & Yes & Yes & $\mathrm{N}$ & $\mathrm{N}$ & $\mathrm{N}$ & $\mathrm{N}$ & $\mathrm{N}$ \\
\hline LHON & $\mathrm{N}$ & $\mathrm{N}$ & $\mathrm{N}$ & $\mathrm{N}$ & $\mathrm{N}$ & $\mathrm{N}$ & $\mathrm{N}$ & $\mathrm{N}$ & Yes & $\mathrm{N}$ \\
\hline PCQD & $\mathrm{N}$ & $\mathrm{N}$ & Yes & $\mathrm{N}$ & $\mathrm{N}$ & $\mathrm{N}$ & $\mathrm{N}$ & Yes & $\mathrm{N}$ & $\mathrm{N}$ \\
\hline XLSA & Yes & $\mathrm{N}$ & $\mathrm{N}$ & $\mathrm{N}$ & $\mathrm{N}$ & $\mathrm{N}$ & $\mathrm{N}$ & $\mathrm{N}$ & $\mathrm{N}$ & $\mathrm{N}$ \\
\hline GRACILE & $\mathrm{N}$ & $\mathrm{N}$ & $\mathrm{N}$ & $\mathrm{N}$ & $\mathrm{N}$ & $\mathrm{N}$ & Yes & $\mathrm{N}$ & $\mathrm{N}$ & $\mathrm{N}$ \\
\hline MEGDEL & Yes & $\mathrm{N}$ & $\mathrm{N}$ & $\mathrm{N}$ & $\mathrm{N}$ & $\mathrm{N}$ & $\mathrm{N}$ & $\mathrm{N}$ & $\mathrm{N}$ & $\mathrm{N}$ \\
\hline HUPRA & Yes & $\mathrm{N}$ & $\mathrm{N}$ & $\mathrm{N}$ & $\mathrm{N}$ & $\mathrm{N}$ & $\mathrm{N}$ & $\mathrm{N}$ & $\mathrm{N}$ & $\mathrm{N}$ \\
\hline MLASA & $\mathrm{N}$ & $\mathrm{N}$ & $\mathrm{N}$ & $\mathrm{N}$ & Yes & $\mathrm{N}$ & $\mathrm{N}$ & $\mathrm{N}$ & $\mathrm{N}$ & $\mathrm{N}$ \\
\hline MSL & $\mathrm{N}$ & $\mathrm{N}$ & $\mathrm{N}$ & $\mathrm{N}$ & Yes & $\mathrm{N}$ & $\mathrm{N}$ & $\mathrm{N}$ & $\mathrm{N}$ & $\mathrm{N}$ \\
\hline PDHD & $\mathrm{N}$ & $\mathrm{N}$ & $\mathrm{N}$ & $\mathrm{N}$ & Yes & $\mathrm{N}$ & $\mathrm{N}$ & $\mathrm{N}$ & $\mathrm{N}$ & $\mathrm{N}$ \\
\hline nsMIMODS & Yes & Yes & Yes & Yes & Yes & $\mathrm{N}$ & $\mathrm{N}$ & Yes & Yes & Yes \\
\hline
\end{tabular}

RF, renal failure; NL, nephrolithiasis; NS, nephrotic syndrome; RC, renal cysts; RTA, renal tubular acidosis; BLS, Bartter-like syndrome; TDFS, Toni-Debré-Fanconi syndrome; FSGS, focal segmental glomerulosclerosis; TIN, tubulo-interstitial nephritis (nephrophthisis); NC, nephrocalcinosis; LS, Leigh syndrome; PCQD, primary coenzyme-Q deficiency; XLSA, X-linked sideroblastic anemia; nsMIMODS, non-specific MIMODS; N, not reported.

findings concerning phenotype, genotype, pathogenesis, diagnosis, treatment and outcome of kidney disease in MIDs.

\section{Methods}

Data for the present review were identified by searching Medical Literature Analysis and Retrieval System Online (MEDLINE; https://www.ncbi.nlm.nih.gov/pubmed), Current Contents (http://wokinfo.com/products_tools/multidisciplinary/CCC/), Excerpta Medica database (EMBASE; https://www.embase. com/login), Web of Science (https://login.webofknowledge. com/error/Error?PathInfo=\%2F\&Alias=WOK $5 \&$ Domain $=$. webof knowledge.com\&Src=IP\&RouterURL=https $\% 3 \mathrm{~A} \% 2 \mathrm{~F} \%$ 2Fwww.webofknowledge.com\%2F\&Error=IPError), Web of Knowledge (https://de.slideshare.net/davehirsty/science-citation-index), Latin American and Caribbean Health Sciences Literature (LILACS; http://bases.bireme.br/cgi-bin/wxislind. exe/iah/online/?IsisScript=iah/iah.xis\&base=LILACS\&lang $=\mathrm{i} \&$ form=F), bibliographic database for science (SCOPUS; https://www.scopus.com/) and Google Scholar (https://scholar. google.de) for references to relevant articles using the following search terms: 'Kidney', 'renal', 'renal insufficiency', 'nephrolithiasis', 'nephrocalcinosis', 'renal cysts', 'Bartter-like syndrome', 'Fanconi syndrome', 'Toni-Debré-Fanconi syndrome', 'nephrotic syndrome', 'tubulointerstitial nephritis', and 'renal tubular acidosis' in combination with all acronyms for syndromic MIDs and the terms 'mtDNA', 'respiratory chain', 'electron transport', 'mitochondrion', and 'mitochondrial'. Randomised (blinded or open label) clinical trials and observational studies (longitudinal studies, case series and case reports) were considered. Abstracts and reports from meetings were not included. Only articles in
English, French, Spanish or German, and those published between 1966 and 2016 were considered. Appropriate papers were evaluated and discussed for their usefulness to be incorporated in the review. Reference lists of the appropriate papers were reviewed for further articles matching the search terms. A paper was included if it reported a single patient or a cohort of patients with MIDs who also manifested with any type of primary or secondary kidney disease.

\section{Results}

Classification. Renal disease in MIDs may be classified as primary or secondary. Secondary kidney disease may result from primary involvement of organs other than the kidneys in the MID. In the case of cardiac involvement in MID, there may be renal infarction from atrial fibrillation or heart failure, or hypertensive kidney disease from mitochondrial arterial hypertension. In the case of mitochondrial diabetes, renal insufficiency may be a consequence of the primary involvement of the pancreas in the MID. Another secondary renal disorder due to a primary mitochondrial defect may be renal insufficiency from rhabdomyolysis due to mitochondrial myopathy or mitochondrial epilepsy (8). Primary renal manifestations of MIDs include acute or chronic renal failure, nephrolithiasis, nephrotic syndrome, renal cysts, renal tubular acidosis (RTA), Bartter-like syndrome, Toni-Debré-Fanconi syndrome (TDFS), focal segmental glomerulosclerosis (FSGS), tubulointerstitial nephritis (TIN), nephrocalcinosis, and benign or malignant neoplasms (9). Renal involvement in MIDs may be classified according to the number of organs that are affected in addition to the kidney. If no other organs are 
Table II. Renal dysfunction in Kearns Sayre syndrome.

\begin{tabular}{|c|c|c|c|c|}
\hline Renal abnormality & Patients, $\mathrm{n}$ & Age, years & Sex & Refs. \\
\hline \multirow[t]{3}{*}{ Renal insufficiency } & 1 & 10 & $\mathrm{~m}$ & 78 \\
\hline & 4 & range, $6-21$ & $\mathrm{f}, 1 ; \mathrm{m}, 3$ & 79 \\
\hline & 1 & NA & NA & 80 \\
\hline \multirow[t]{2}{*}{ Renal tubular acidosis } & 1 & 7 & $\mathrm{~m}$ & 32 \\
\hline & 1 & 18 & $\mathrm{f}$ & 33 \\
\hline \multirow[t]{3}{*}{ Bartter-like syndrome } & 1 & 14 & $\mathrm{~m}$ & 13 \\
\hline & 1 & 7 & $\mathrm{f}$ & 35 \\
\hline & 1 & 10 & $\mathrm{~m}$ & 34 \\
\hline \multirow[t]{8}{*}{ Toni-Debré-Fanconi syndrome } & 1 & 11 & $\mathrm{f}$ & 15 \\
\hline & 1 & 10 & $\mathrm{~m}$ & 27 \\
\hline & 1 & 10 & $\mathrm{~m}$ & 28 \\
\hline & 1 & 5 & $\mathrm{~m}$ & 29 \\
\hline & 1 & 18 & $\mathrm{~m}$ & 30 \\
\hline & 1 & 8 & $\mathrm{f}$ & 31 \\
\hline & 1 & 43 & $\mathrm{f}$ & 14 \\
\hline & 1 & 13 & $\mathrm{f}$ & 26 \\
\hline
\end{tabular}

f, female; m, male; NA, not accessible.

additionally involved (absence of MIMODS) the mitochondrial nature of renal disease is often difficult to detect (10). However, when more organs are affected, it is more suggestive of a MID. Additionally, renal involvement may be classified according to the priority within the phenotype. In certain cases, renal involvement may dominate the phenotype whereas in other cases, renal disease may be a non-dominant feature. A further differentiation of renal involvement in MIDs relies on whether the underlying genotype manifests clinically or remains subclinical. Subclinical involvement may be detected upon observation of morphological abnormalities of mitochondria and a high quantity of heteroplasmy of mutated mtDNA during kidney biopsy or autopsy $(11,12)$.

Renal disease in syndromic MIDs. Renal involvement has been reported in a number of syndromic MIDs, which predominantly include mitochondrial encephalomyopathy, lactic acidosis, and stroke-like episodes (MELAS), Kearns Sayre syndrome (KSS; Table II) $(13,14)$ and mitochondrial depletion syndromes (MDSs). On rare occasions, renal disease may be found in other rarer types of syndromic MIDs.

MELAS. MELAS is one of the syndromic MIDs in which renal disease is fairly frequent. In a 14-year-old female with MELAS syndrome, the initial manifestation of the MID was an FSGS, which occurred 3 years prior to diagnosis of the MID (15). In a 35-year-old female with MELAS syndrome resulting from the $\mathrm{m} .13513 \mathrm{G}>\mathrm{A}$ mutation, renal failure was the initial manifestation of the MID 9 years before diagnosis of the MID (10). In a 50-year-old male with MELAS syndrome, chronic renal failure requiring hemodialysis was one of the clinical manifestations (16). Chronic renal failure was the indication for renal transplantation in a 58-year-old male with MELAS syndrome (17). In a 13-year-old Asian female with MELAS syndrome, renal involvement manifested as FSGS (18). In another MELAS patient acute renal failure occurred and was associated with severe hyponatriemia due to renal sodium loss (19). Furthermore, in a female MELAS syndrome patient, severe kidney involvement with changes of FSGS was reported (20). Acute or chronic renal failure has been also reported in a number of MELAS patients with or without diabetes, suggesting that renal dysfunction is primary or secondary (21). In a series of 5 MELAS patients, FSGS was a phenotypic feature in all of them; thus, the authors concluded that renal involvement in MELAS may be underestimated (7). Chronic renal failure appears to be a typical manifestation of MELAS (22) and FSGS may be the dominant feature in these patients (23). Kidney cancer was reported in a 41-year-old male who was exhibiting MELAS syndrome (24). A histological work-up additionally revealed arteriolonephrosclerosis (24) and renal cell carcinoma was reported in a 2-year-old male with MELAS syndrome (25).

KSS. Renal abnormalities so far described in KSS include renal failure, RTA, Bartter-like syndrome and TDFS (Table II). In an 11-year-old female with KSS, TDFS was diagnosed 8 years prior to the diagnosis of the MID (15). TDFS was also reported in a 13-year-old female with KSS who additionally manifested with anhidrosis (26), as well as other patients (14,27-31). In a 5-year-old male with KSS, the MID manifested with RTA (Table II) (32), which was also described in an 18-year-old female (Table II) (33). In a 10-year-old male with KSS, the MID manifested in the kidneys as renal tubular dysfunction with isosthenuria, decreased urine-concentrating ability, and excessive excretion of potassium and magnesium (34). In addition, hyperreninemia and hyperaldosteronism were 
Table III. Genes in which mutations cause MID with renal involvement.

\begin{tabular}{|c|c|c|}
\hline Mutated gene & Renal disease & Refs. \\
\hline \multicolumn{3}{|l|}{ mtDNA } \\
\hline tRNA(Leu) & RF, FSGS & $(16,81)$ \\
\hline tRNA(Phe) & Tubulointerstitial fibrosis, RF, TDFS & $(74,82)$ \\
\hline tRNA(Tyr) & FSGS, nephrotic syndrome & $(75)$ \\
\hline tRNA(Ser) & Proteinurea, glomerulosclerosis & $(66)$ \\
\hline COXIII & $\mathrm{RF}$ & $(83)$ \\
\hline \multicolumn{3}{|l|}{ nDNA } \\
\hline COX10 & Tubulopathy & $(65)$ \\
\hline SURF1 & RTA & $(48)$ \\
\hline BCS1L & Proximal tubulopathy & $(68)$ \\
\hline UQCC1 & Tubulopathy & $(72)$ \\
\hline TMEM70 & RTA, RF, hydronephrosis & $(69)$ \\
\hline MRPS22 & Tubulopathy & $(71)$ \\
\hline YARS2 & Tubulopathy & $(53)$ \\
\hline SARS2 & Tubulopathy & $(49)$ \\
\hline RRM2B & Proximal tubulopathy, $\mathrm{NC}$ & $(36,40,41,84)$ \\
\hline TWINKLE & Proximal tubulopathy & $(38)$ \\
\hline MPV17 & Tubulopathy & $(43)$ \\
\hline DGUOK & Tubulopathy & $(42)$ \\
\hline LARS2 & $\mathrm{RF}$ & $(70)$ \\
\hline RMND1 & Chronic RF & $(73)$ \\
\hline ACAD9 & Megamitochondria in tubules & $(54)$ \\
\hline CLPB & Nephrocalcinosis, cysts, aciduria & $(85)$ \\
\hline ADCK4 & Nephrotic syndrome & $(77,78)$ \\
\hline MRPL44 & Renal failure & $(86)$ \\
\hline
\end{tabular}

RF, renal failure; RTA, renal tubular acidosis; NC, nephrocalcinosis.

present in the absence of arterial hypertension, resulting in a diagnosis of Bartter-like syndrome (34). Furthermore, Bartter-like syndrome has been described in two other patients with KSS, in a 14-year-old male (13) and a 7-year-old female (Table II) (35). In addition, nephrocalcinosis has been identified as a rare feature of $\mathrm{KSS}(13)$.

$M D S$. MDSs are characterised by a reduction in the quantity of mtDNA within a mitochondrion of a cell. MDSs are due to mutations in the ribonucleotide reductase regulatory TP53 inducible subunit M2B (RRM2B), MpV17 mitochondrial inner membrane protein (MPV17), DNA polymerase $\gamma$, catalytic subunit (POLG1), DNA polymerase $\gamma 2$, accessory subunit (POLG2), succinate-CoA ligase ADP-forming $\beta$ subunit (SUCLA2), succinate-CoA ligase GDP-forming $\beta$ subunit (SUCLG2), twinkle mtDNA helicase (C10orf2), deoxyguanosine kinase $(D G U O K)$, thymidine kinase 2 , mitochondrial (TK2), F-box and leucine rich repeat protein 4 (FBXL4), and transcription factor A, mitochondrial (TFAM) genes, In an infant with MDS due to a mutation in the RRM2B gene, the MID manifested along with proximal renal tubulopathy and nephrocalcinosis (36). In an infant with MDS, but without detection of the underlying genetic defect, RTA developed 1 year after liver transplantation and was attributed to tacrolimus toxicity and renal involvement in the MID (37). In three siblings with MDS due to a C10orf2 (twinkle) mutation, the MDS manifested as hepatocerebral syndrome and as proximal renal tubulopathy (Table III) (38). Renal tubulopathy was also reported in a female newborn with MDS carrying an mtDNA copy number of only $2 \%$ (39). In one of two males with MDS due to a mutation in the $R R M 2 B$ gene, proximal renal tubulopathy was described (40). Tubulopathy was also present in a female infant with MDS carrying the $R R M 2 B$ mutation c.368T $>C$ (41). In addition, tubulopathy was detected in three patients during an investigation of 11 patients with MDS due to mutations in the DGUOK gene (42). Furthermore, MDS resulting from mutations in the MPV17 gene may be associated with tubulopathy (Table III) (43).

Other syndromic MIDs with renal involvement. Single cases of renal involvement have been reported in other syndromic MIDs, such as chronic progressive external ophthalmoplegia (CPEO) (44), Pearson syndrome (45), Leber hereditary optic neuropathy (LHON) (46), coenzyme-Q deficiency, X-linked sideroblastic anemia (XLSA) (47), Leigh syndrome (48), or hyperuricemia, metabolic alkalosis, pulmonary hypertension, and progressive renal failure in infancy (HUPRA) syndrome (49). In a 44-year-old female with CPEO, the MID 
initially manifested initially with hearing loss at age 22 years, which was followed by renal failure at 30 years of age (44). In an infant with Pearson syndrome due to a single mtDNA deletion, the bone marrow, central nervous system, exocrine pancreas and the kidneys were involved. Renal involvement manifested as severe tubular dysfunction (45). In another patient with Pearson syndrome multiple renal cysts were reported (50). In a 1-year-old female with LHON, renal involvement manifested as nephronophthisis, also referred to as TIN (46). In an infant with primary coenzyme-Q deficiency due to a mutation in the $C O Q 2$ gene, the MID manifested with nephrotic syndrome due to FSGS (51). In an 81-year-old male with XLSA due to mutations in the ALAS2 gene, renal involvement manifested as severe renal failure requiring haemodialysis (47). In a study of four patients with Leigh syndrome due to a mutation in the SURFl gene, three had significant proximal RTA (48). Hyperuricemia, pulmonary hypertension, renal failure in infancy and alkalosis (HUPRA) syndrome due to SARS2 gene mutations is, by definition, a rare MID that presents along with renal failure (52). In two Palestinian infants with HUPRA syndrome due to a SARS2 mutation, tubulopathy was a cardinal phenotypic feature of the disease (49). In a Turkish family with myopathy, lactic acidosis, and sideroblastic anaemia (MLASA) syndrome due to a YARS2 mutation, renal involvement manifested as tubulopathy (53). In a neonate with Leigh syndrome due to a mutation in the $A C A D 9$ gene, autopsy revealed hyperplasia of mitochondria in renal tubular cells (54). In addition, in a patient with Leigh syndrome due to a mutation in the ND5 gene renal salt loss was deemed responsible for secondary hyponatriemia (55). Diffuse glomerulocystic kidneys were reported in a patient with Leigh syndrome, but without detecting the genetic defect (56). Growth retardation, aminoaciduria, cholestasis, iron overload, lactic acidosis and early death (GRACILE) syndrome is an early-onset, autosomal recessive multisystem MID due to mutations in the $B C S 1 L$ gene. Clinically, GRACILE syndrome is characterised by fetal growth retardation, Fanconi-type aminoaciduria, cholestasis, iron overload, profound lactic acidosis, and early mortality (57). One of the clinical hallmarks of GRACILE syndrome is TDFS-type tubulopathy with aminoaciduria. In a mouse model of GRACILE syndrome, tubulopathy was one of various other phenotypic features (58). Late-onset nephrotic syndrome was described in Mpv17 knock-out mice (59). In single patients with multiple systemic lipomatosis, which may be due to the m.8344A $>\mathrm{G}$ mutation, RTA has been reported (60). In a male infant with pyruvate dehydrogenase deficiency (PDH), RTA was one of the clinical manifestations in addition to lactic acidosis, contributing to the death of this individual (61). Whether renal excretion of urinary phosphatidylethanolamine, cardiolipin, and phosphatidylserine in four patients with myoclonus epilepsy with ragged-red fibres (MERRF) (62) and in one patient with CPEO was truly attributable to renal involvement remains unknown, but they may be derived from sulfatides, which are specific to the kidneys (62).

Renal disease in non-specific syndromic MIDs. In four adult patients with FSGS, kidney disease was attributed to an MID, as renal biopsy revealed the presence of the m.3243A $>\mathrm{G}$ mutation in the $\operatorname{tRNA}(\mathrm{Leu})$ gene (61). Notably, no other organs were affected in these four patients; thus, kidney disease was the initial manifestation and dominant feature of the MID and, therefore, the phenotype was not consistent with MELAS syndrome at the time of diagnosis (63). In a patient with sensorineural blindness, attributed to a non-genetically proven MID, Bartter-like syndrome was the second phenotypic feature (64). In a consanguineous family with isolated COX-deficiency due to a mutation in the COX10 gene, which encodes the heme A:farnesyltransferase, increased urinary amino acids suggested proximal renal tubulopathy (65). In a 54-year-old female, the homoplasmic m.7501T $>$ A mutation in the $t R N A(\mathrm{Ser})$ gene manifested as proteinurea due to sclerosis of one-quarter of the glomeruli observed during kidney biopsy (66). Almost one-third of the interstitium was fibrotic in this patient. Tubular granular swollen epithelial cells (GSECs), which have been demonstrated to indicate a MID (67), were present in the medulla collecting ducts (66). In a study of six patients with encephalopathy, hepatopathy, and proximal tubulopathy, the causative mutation was detected in the BCSIL gene resulting in respiratory chain complex III deficiency (68). In a study of 35 multi-ethnic patients carrying a TMEM70 mutation, $35 \%$ manifested with renal disease in the form of RTA, hydronephrosis and acute or chronic renal failure (69). In a newborn girl with MIMODS due to a mutation in the LARS2 gene, encoding for a mitochondrial amino-acyl-tRNA synthetase, progressive renal failure was responsible for mortality 5 days after birth (70). In three children from the same consanguineous parents, antenatal skin oedema, hypotonia, cardiomyopathy and tubulopathy were attributed to mutations in the MRPS22 gene (71). In a consanguineous Lebanese patient with respiratory chain complex III deficiency due to a UQCC2 gene mutation, renal tubulopathy was one of the phenotypic manifestations, in addition to severe intrauterine growth retardation and neonatal lactic acidosis (72). Chronic renal failure was also reported in an 11-month-old male who presented with truncal ataxia, sensorineural hearing loss, muscle hypotonia, delayed visual maturation, global developmental delay and dilated cardiomyopathy (73). Nuclear genetic studies identified a causative mutation in the RMNDl gene (73). End-stage renal disease due to TIF was reported in a 16-month-old girl with developmental regression, lactic acidosis, hypotonia, gastrointestinal dysmotility, adrenal insufficiency, arterial hypertension and haematological abnormalities carrying a $t R N A(P h e)$ mutation (74). Isolated renal disease as the sole manifestation of a MID was reported in a 9-year-old female with steroid-resistant FSGS (75). The MID was due to a point mutation in the mtDNA located at the $t R N A(T y r)$ gene (75).

Diagnosis. A diagnostic work-up of renal disease in MIDs is not different from a work-up of renal disease in patients without an MID. The diagnosis is based on blood tests, urine analysis, imaging, functional tests and biopsies. Biopsy is important, as it may show abnormalities, which have been reported in MID patients with renal involvement (Table I), as well as morphological abnormalities of mitochondria. A strong indicator for the mitochondrial nature of a kidney disease appears to be the presence of GSECs. MID patients with suspected renal involvement should, therefore, undergo kidney biopsy, to establish whether GSECs are present. In addition, a biopsy may show microvascular degeneration of the renal tubular epithelial cells, such as in Leigh syndrome. 
If additional biochemical investigations are performed, dysfunction of one or various respiratory chain complexes may be detected. If genetic studies are conducted, mutations in mtDNA- or nDNA-located genes may be detected (Table III) and, in the case of mtDNA mutations, the heteroplasmy rates may be determined. Notably, a single patient may present with more than one renal abnormality (Table I).

Treatment. Treatment of mitochondrial nephropathy is the same as for non-mitochondrial nephropathy. However, drugs that are mitochondrion-toxic should generally be avoided in MID patients. Though not supported by evidence from appropriate clinical trials, mitochondrial nephropathy may respond to supportive treatment administered to MID patients, such as antioxidants, co-factors or vitamins (76). In patients with steroid resistant nephrotic syndrome due to mutations in the ADCK4 gene, which is involved in COQ10 biosynthesis, coenzyme-Q may be highly beneficial (77). Renal failure in MIDs may be of such a degree that haemodialysis may be required.

Outcome. To the best of our knowledge, there are no available systematic studies regarding the outcome of renal disease in MIDs. The outcome of renal involvement in MIDs is dependent on the underlying mutation, as well as the type of renal disease. The outcome of renal disease in MIDs is also dependent on whether it is primary or secondary. In the case of mtDNA mutations, the heteroplasmy rate in the kidneys may be significant for the outcome of renal disease. Though not systematically investigated, it is speculated that the severity of renal disease increases and that the outcome of kidney disease becomes worse as the heteroplasmy rate increases.

\section{Conclusion}

The present review demonstrates that renal involvement in MIDs is more frequent than originally anticipated, and that primary and secondary renal involvement in MIDs occurs in syndromic and non-syndromic MIDs. Among the syndromic MIDs renal involvement has been most frequently reported in MELAS syndrome, KSS and MDS. Only rarely was renal involvement described in patients with CPEO, Pearson syndrome, LHON, primary coenzyme-Q deficiency, XLSA, Leigh syndrome, PDH deficiency, GR ACILE syndrome HUPRA syndrome, or non-specific syndromic MIDs. Primary renal involvement in MIDs includes renal failure, nephrolithiasis, nephrotic syndrome, renal cysts, renal tubular acidosis, Bartter-like syndrome, Fanconi syndrome, FSGS, TIN, nephrocalcinosis and neoplasms. Bartter-like syndrome is characterised by a hyperreninemic hyperaldosteronism, hyponatriemia, hypokaliemia, hypo-osmolarity, arterial hypotension despite hyperreninemic hyperaldosteronism and alkalosis.

Diagnosis of renal involvement in MIDs is the same as diagnosing renal disease in non-MID patients. In MID patients with a Bartter-like syndrome, Bartter syndrome must be excluded by showing absence of a mutation in the SLC12AI (type 1), KCNJ1 (type 2), ClCNKb (type 3), BSND (type 4), or the $C S A R$ gene (type 5). If mitochondrial nephropathy is the initial manifestation of an MID, diagnosing the MID may be delayed unless genetic or biochemical investigations are performed with renal biopsies. In particular, patients with one of the frequent renal manifestations of MID should be closely followed up for establishing whether organs other than the kidneys have been affected, and first-degree relatives must be thoroughly investigated for MID. Treatment of renal disease in MIDs follows general guidelines, however, physicians must be wary of prescribing mitochondrion-toxic compounds, which could worsen renal disease and involvement of other organs in MIDs. Antioxidants, vitamins, and other co-factors may be of additional benefit for renal disease in MIDs, but, to the best of our knowledge, no systematic studies have been performed addressing these issues. The focus of future research in MIDs should be directed towards mitochondrial nephropathy, and optimized diagnostic and therapeutic procedures must be established. From a translational perspective, animal models may provide important mechanistic insights into MIDs and may be particularly useful for the development of novel compounds for improving the therapeutic options in MIDs.

\section{References}

1. Finsterer J: Inherited mitochondrial disorders. Adv Exp Med Biol 942: 187-213, 2012.

2. McFarland R, Taylor RW and Turnbull DM: A neurological perspective on mitochondrial disease. Lancet Neurol 9: 829-840, 2010.

3. Finsterer J and Zarrouk-Mahjoub S: Mitochondrial Disorders May Mimic Amyotrophic Lateral Sclerosis at Onset. Sultan Qaboos Univ Med J 16: e92-e95, 2016.

4. Emma F, Montini G, Parikh SM and Salviati L: Mitochondrial dysfunction in inherited renal disease and acute kidney injury. Nat Rev Nephrol 12: 267-280, 2016.

5. Niaudet P: Renal involvement in mitochondrial cytopathies. Nephrol Ther 9: 116-124, 2013 (In French).

6. Emma F, Bertini E, Salviati L and Montini G: Renal involvement in mitochondrial cytopathies. Pediatr Nephrol 27: 539-550, 2012.

7. Seidowsky A, Hoffmann M, Glowacki F, Dhaenens CM, Devaux JP, de Sainte Foy CL, Provot F, Gheerbrant JD, Hummel A, Hazzan M, et al: Renal involvement in MELAS syndrome - a series of 5 cases and review of the literature. Clin Nephrol 80: 456-463, 2013.

8. Yokoyama J, Yamaguchi H, Shigeto H, Uchiumi T, Murai H and Kira J: A case of rhabdomyolysis after status epilepticus without stroke-like episodes in mitochondrial myopathy, encephalopathy, lactic acidosis, and stroke-like episodes. Rinsho Shinkeigaku 56: 204-207, 2016 (In Japanese).

9. Finsterer J and Frank M: Prevalence of neoplasms in definite and probable mitochondrial disorders. Mitochondrion 29: 31-34, 2016.

10. Motoda A, Kurashige T, Sugiura T, Nakamura T, Yamawaki T, Arihiro K and Matsumoto M: A case of MELAS with G13513A mutation presenting with chronic kidney disease long before stroke-like episodes. Rinsho Shinkeigaku 53: 446-451, 2013 (In Japanese).

11. Ponzetto C, Bresolin N, Bordoni A, Moggio M, Meola G, Bet L, Prelle A and Scarlato G: Kearns-Sayre syndrome: Different amounts of deleted mitochondrial DNA are present in several autoptic tissues. J Neurol Sci 96: 207-210, 1990.

12. Bresolin N, Moggio M, Bet L, Gallanti A, Prelle A Nobile-Orazio E, Adobbati L, Ferrante C, Pellegrini G and Scarlato G: Progressive cytochrome c oxidase deficiency in a case of Kearns-Sayre syndrome: Morphological, immunological, and biochemical studies in muscle biopsies and autopsy tissues. Ann Neurol 21: 564-572, 1987.

13. Emma F, Pizzini C, Tessa A, Di Giandomenico S, Onetti-Muda A, Santorelli FM, Bertini E and Rizzoni G: 'Bartter-like' phenotype in Kearns-Sayre syndrome. Pediatr Nephrol 21: 355-360, 2006.

14. Berio A and Piazzi A: Kearns-Sayre syndrome associated with de Toni-Debré-Fanconi syndrome due to cytochrome-c-oxidase (COX) deficiency. Panminerva Med 43: 211-214, 2001. 
15. Mochizuki H,Joh K, Kawame H,Imadachi A, Nozaki H, Ohashi T, Usui N,Eto Y, Kanetsuna Y and Aizawa S: Mitochondrial encephalomyopathies preceded by de-Toni-Debré-Fanconi syndrome or focal segmental glomerulosclerosis. Clin Nephrol 46: 347-352, 1996.

16. Mima A, Shiota F, Matsubara T, Iehara N, Akagi T, Abe H, Nagai K, Matsuura M, Murakami T, Kishi S, et al: An autopsy case of mitochondrial myopathy, encephalopathy, lactic acidosis, and stroke-like episodes (MELAS) with intestinal bleeding in chronic renal failure. Ren Fail 33: 622-625, 2011.

17. Lederer SR, Klopstock T and Schiffl H: MELAS: A mitochondrial disorder in an adult patient with a renal transplant. Wien Klin Wochenschr 122: 363-365, 2010.

18. Lau KK, Yang SP, Haddad MN, Butani L and Makker SP: Mitochondrial encephalopathy with lactic acidosis and stroke-like episodes syndrome with hypothyroidism and focal segmental glomerulosclerosis in a paediatric patient. Int Urol Nephrol 39: 941-946, 2007.

19. Kubota H, Tanabe Y, Takanashi J and Kohno Y: Episodic hyponatremia in mitochondrial encephalomyopathy, lactic acidosis, and strokelike episodes (MELAS). J Child Neurol 20: 116-120, 2005.

20. Cheong HI, Chae JH, Kim JS, Park HW, Ha IS, Hwang YS, Lee HS and Choi Y: Hereditary glomerulopathy associated with a mitochondrial tRNA(Leu) gene mutation. Pediatr Nephrol 13: 477-480, 1999.

21. Iwasaki N, Babazono T, Tsuchiya K, Tomonaga O, Suzuki A, Togashi M, Ujihara N, Sakka Y, Yokokawa H, Ogata M, et al: Prevalence of A-to-G mutation at nucleotide 3243 of the mitochondrial tRNA(Leu(UUR)) gene in Japanese patients with diabetes mellitus and end stage renal disease. J Hum Genet 46 : 330-334, 2001

22. Yanagihara C, Oyama A, Tanaka M, Nakaji K and Nishimura $Y$ : An autopsy case of mitochondrial encephalomyopathy with lactic acidosis and stroke-like episodes syndrome with chronic renal failure. Intern Med 40: 662-665, 2001.

23. Kurogouchi F, Oguchi T, Mawatari E, Yamaura S, Hora K, Takei M, Sekijima Y, Ikeda S and Kiyosawa K: A case of mitochondrial cytopathy with a typical point mutation for MELAS presenting with severe focal-segmental glomerulosclerosis as main clinical manifestation. Am J Nephrol 18: 551-556, 1998.

24. Piccoli GB, Bonino LD, Campisi P, Vigotti FN, Ferraresi M, Fassio F, Brocheriou I, Porpiglia F and Restagno G: Chronic kidney disease, severe arterial and arteriolar sclerosis and kidney neoplasia: On the spectrum of kidney involvement in MELAS syndrome. BMC Nephrol 13: 9, 2012.

25. Sangkhathat S, Kusafuka T, Yoneda A, Kuroda S, Tanaka Y, Sakai $\mathrm{N}$ and Fukuzawa M: Renal cell carcinoma in a pediatric patient with an inherited mitochondrial mutation. Pediatr Surg Int 21: 745-748, 2005

26. Mori K, Narahara K, Ninomiya S, Goto Y and Nonaka I: Renal and skin involvement in a patient with complete Kearns-Sayre syndrome. Am J Med Genet 38: 583-587, 1991.

27. Ho J, Pacaud D, Rakic M and Khan A: Diabetes in pediatric patients with Kearns-Sayre syndrome: Clinical presentation of 2 cases and a review of pathophysiology. Can J Diabetes 38 $225-228,2014$

28. Liu HM, Tsai LP, Chien YH, Wu JF, Weng WC, Peng SF, Wu ET, Huang PH, Lee WT, Tsai IJ, et al: A novel 3670-base pair mitochondrial DNA deletion resulting in multi-systemic manifestations in a child. Pediatr Neonatol 53: 264-268, 2012

29. Tzoufi M, Makis A, Chaliasos N, Nakou I, Siomou E, Tsatsoulis A, Zikou A, Argyropoulou M, Bonnefont JP and Siamopoulou A: A rare case report of simultaneous presentation of myopathy, Addison's disease, primary hypoparathyroidism, and Fanconi syndrome in a child diagnosed with Kearns-Sayre syndrome. Eur J Pediatr 172: 557-561, 2013.

30. Mihai CM, Catrinoiu D, Toringhibel M, Stoicescu RM and Hancu A: De Toni-Debré-Fanconi syndrome in a patient with Kearns-Sayre syndrome: A case report. J Med Case Reports 3: 101, 2009.

31. Pitchon EM, Cachat F, Jacquemont S, Hinard C, Borruat FX, Schorderet DF, Morris MA and Munier FL: Patient with Fanconi Syndrome (FS) and retinitis pigmentosa (RP) caused by a deletion and duplication of mitochondrial DNA (mtDNA). Klin Monatsbl Augenheilkd 224: 340-343, 2007.

32. Eviatar L, Shanske S, Gauthier B, Abrams C, Maytal J, Slavin M, Valderrama E and DiMauro S: Kearns-Sayre syndrome presenting as renal tubular acidosis. Neurology 40: 1761-1763, 1990.
33. Katsanos KH, Elisaf M, Bairaktari E and Tsianos EV: Severe hypomagnesemia and hypoparathyroidism in Kearns-Sayre syndrome. Am J Nephrol 21: 150-153, 2001.

34. Goto Y, Itami N, Kajii N, Tochimaru H, Endo M and Horai S: Renal tubular involvement mimicking Bartter syndrome in a patient with Kearns-Sayre syndrome. J Pediatr 116: 904-910, 1990.

35. Choe Y, Park E, Hyun HS, Ko JM, Kang HG, Kim JH, Park SH and Cheong HI: A 7-year-old girl presenting with a Bartter-like phenotype: Answers. Pediatr Nephrol (In press).

36. Stojanovic V, Mayr JA, Sperl W, Barišić N, Doronjski A and Milak G: Infantile peripheral neuropathy, deafness, and proximal tubulopathy associated with a novel mutation of the RRM2B gene: Case study. Croat Med J 54: 579-584, 2013.

37. De Greef E, Christodoulou J, Alexander IE, Shun A, O'Loughlin EV, Thorburn DR, Jermyn V and Stormon MO: Mitochondrial respiratory chain hepatopathies: Role of liver transplantation. A case series of five patients. JIMD Rep 4: 5-11, 2012.

38. Prasad C, Melançon SB, Rupar CA, Prasad AN, Nunez LD, Rosenblatt DS and Majewski J: Exome sequencing reveals a homozygous mutation in TWINKLE as the cause of multisystemic failure including renal tubulopathy in three siblings. Mol Genet Metab 108: 190-194, 2013

39. Lee IC, Lee NC, Lu JJ and Su PH: Mitochondrial depletion causes neonatal-onset leigh syndrome, myopathy, and renal tubulopathy. J Child Neurol 28: 404-408, 2013.

40. Kollberg G, Darin N, Benan K, Moslemi AR, Lindal S, Tulinius M, Oldfors A and Holme E: A novel homozygous RRM2B missense mutation in association with severe mtDNA depletion. Neuromuscul Disord 19: 147-150, 2009.

41. Acham-Roschitz B, Plecko B, Lindbichler F, Bittner R, Mache CJ, Sperl W and Mayr JA: A novel mutation of the RRM2B gene in an infant with early fatal encephalomyopathy, central hypomyelination, and tubulopathy. Mol Genet Metab 98: 300-304, 2009

42. Dimmock DP, Zhang Q, Dionisi-Vici C, Carrozzo R, Shieh J, Tang LY, Truong C, Schmitt E, Sifry-Platt M, Lucioli S, et al: Clinical and molecular features of mitochondrial DNA depletion due to mutations in deoxyguanosine kinase. Hum Mutat 29: 330-331, 2008.

43. El-Hattab AW and Scaglia F: Mitochondrial DNA depletion syndromes: Review and updates of genetic basis, manifestations, and therapeutic options. Neurotherapeutics 10: 186-198, 2013.

44. Yuri T, Kondo Y, Kohno K, Lei YC, Kanematsu S, Kuwata M, Iwasaka T and Tsubura A: An autopsy case of chronic progressive external ophthalmoplegia with renal insufficiency. Med Mol Morphol 41: 233-237, 2008.

45. Majander A, Suomalainen A, Vettenranta K, Sariola H, Perkkiö M, Holmberg C and Pihko H: Congenital hypoplastic anemia, diabetes, and severe renal tubular dysfunction associated with a mitochondrial DNA deletion. Pediatr Res 30: 327-330, 1991.

46. Singh V, Bhattacharjee S, Singh K and Narula MK: Leber's amaurosis with nephronophthisis and congenital hepatic fibrosis. Indian Pediatr 41: 1053-1056, 2004.

47. Furuyama K, Harigae H, Kinoshita C, Shimada T, Miyaoka K, Kanda C, Maruyama Y, Shibahara S and Sassa S: Late-onset $\mathrm{X}$-linked sideroblastic anemia following hemodialysis. Blood 101: 4623-4624, 2003

48. Tay SK, Sacconi S, Akman HO, Morales JF, Morales A De Vivo DC, Shanske S, Bonilla E and DiMauro S: Unusual clinical presentations in four cases of Leigh disease, cytochrome $\mathrm{C}$ oxidase deficiency, and SURF1 gene mutations. J Child Neurol 20: 670-674, 2005 .

49. Belostotsky R, Ben-Shalom E, Rinat C, Becker-Cohen R, Feinstein S, Zeligson S, Segel R, Elpeleg O, Nassar S and Frishberg Y: Mutations in the mitochondrial seryl-tRNA synthetase cause hyperuricemia, pulmonary hypertension, renal failure in infancy and alkalosis, HUPRA syndrome. Am J Hum Genet 88: 193-200, 2011.

50. Gürgey A, Ozalp I, Rötig A, Coşkun T, Tekinalp G, Erdem G, Akeören Z, Caglar M and Bakkaloglu A: A case of Pearson syndrome associated with multiple renal cysts. Pediatr Nephrol 10: 637-638, 1996

51. Scalais E, Chafai R, Van Coster R, Bindl L, Nuttin C, Panagiotaraki C, Seneca S, Lissens W, Ribes A, Geers C, et al: Early myoclonic epilepsy, hypertrophic cardiomyopathy and subsequently a nephrotic syndrome in a patient with CoQ10 deficiency caused by mutations in para-hydroxybenzoate-polyprenyl transferase (COQ2). Eur J Paediatr Neurol 17: 625-630, 2013. 
52. Rivera H, Martín-Hernández E, Delmiro A, García-Silva MT, Quijada-Fraile P, Muley R, Arenas J, Martín MA and Martínez-Azorín F: A new mutation in the gene encoding mitochondrial seryl-tRNA synthetase as a cause of HUPRA syndrome. BMC Nephrol 14: 195, 2013.

53. Nakajima J, Eminoglu TF, Vatansever G, Nakashima M, Tsurusaki Y, Saitsu H, Kawashima H, Matsumoto N and Miyake N: A novel homozygous YARS2 mutation causes severe myopathy, lactic acidosis, and sideroblastic anemia 2. J Hum Genet 59: 229-232, 2014.

54. Leslie N, Wang X, Peng Y, Valencia CA, Khuchua Z, Hata J, Witte D, Huang T and Bove KE: Neonatal multiorgan failure due to ACAD9 mutation and complex I deficiency with mitochondrial hyperplasia in liver, cardiac myocytes, skeletal muscle, and renal tubules. Hum Pathol 49: 27-32, 2016.

55. Brecht M, Richardson M, Taranath A, Grist S, Thorburn D and Bratkovic D: Leigh Syndrome Caused by the MT-ND5 m.13513G>A Mutation: A Case Presenting with WPW-Like Conduction Defect, Cardiomyopathy, Hypertension and Hyponatraemia. JIMD Rep 19: 95-100, 2015.

56. Yamakawa T, Yoshida F, Kumagai T, Watanabe H, Takano A Mizuno M, Ikeguchi H, Morita Y, Sobue G and Matsuo S: Glomerulocystic kidney associated with subacute necrotizing-encephalomyelopathy. Am J Kidney Dis 37: E14, 2001.

57. Kasapkara CS, Tümer L, Ezgü FS, Küçükçongar A and Hasanoğlu A: BCS1L gene mutation causing GRACILE syndrome: Case report. Ren Fail 36: 953-954, 2014.

58. Levéen P, Kotarsky H, Mörgelin M, Karikoski R, Elmér E and Fellman V: The GRACILE mutation introduced into Bcs1l causes postnatal complex III deficiency: A viable mouse model for mitochondrial hepatopathy. Hepatology 53: 437-447, 2011.

59. Viscomi C, Spinazzola A, Maggioni M, Fernandez-Vizarra E, Massa V, Pagano C, Vettor R, Mora M and Zeviani M: Early-onset liver mtDNA depletion and late-onset proteinuric nephropathy in Mpv17 knockout mice. Hum Mol Genet 18: 12-26, 2009.

60. Dabrowska A, Tarnowska C, Jałowinski R, Stankiewicz J and Grzegorz M: Multiple symmetric lipomatosis in the otolaryngology as diagnostic and therapeutic problem. Otolaryngo Pol 59: 717-722, 2005 (In Polish).

61. Yoshida I, Sweetman L, Kulovich S, Nyhan WL and Robinson BH: Effect of lipoic acid in a patient with defective activity of pyruvate dehydrogenase, 2-oxoglutarate dehydrogenase, and branched-chain keto acid dehydrogenase. Pediatr Res 27: 75-79, 1990.

62. Uyama E, Kutsukake Y, Hara A, Uemura K, Uchino M, Mita S, Ando $\mathrm{M}$ and Taketomi T: Abnormal excretion of urinary phospholipids and sulfatide in patients with mitochondrial encephalomyopathies. Biochem Biophys Res Commun 194: 266-273, 1993

63. Doleris LM, Hill GS, Chedin P, Nochy D, Bellanne-Chantelot C, Hanslik T, Bedrossian J, Caillat-Zucman S, Cahen-Varsaux J and Bariety J: Focal segmental glomerulosclerosis associated with mitochondrial cytopathy. Kidney Int 58: 1851-1858, 2000

64. Menegon LF, Amaral TN and Gontijo JA: Renal sodium handling study in an atypical case of Bartter's syndrome associated with mitochondriopathy and sensorineural blindness. Ren Fail 26: 195-197, 2004

65. Valnot I, von Kleist-Retzow JC, Barrientos A, Gorbatyuk M, Taanman JW, Mehaye B, Rustin P, Tzagoloff A, Munnich A and Rötig A: A mutation in the human heme A:farnesyltransferase gene (COX10 ) causes cytochrome c oxidase deficiency. Hum Mol Genet 9: 1245-1249, 2000.

66. Imasawa T, Tanaka M, Yamaguchi Y, Nakazato T, Kitamura $\mathrm{H}$ and Nishimura M: $7501 \mathrm{~T}>\mathrm{A}$ mitochondrial DNA variant in a patient with glomerulosclerosis. Ren Fail 36: 1461-1465, 2014.

67. Kobayashi A, Goto Y, Nagata M and Yamaguchi Y: Granular swollen epithelial cells: A histologic and diagnostic marker for mitochondrial nephropathy. Am J Surg Pathol 34: 262-270, 2010.

68. de Lonlay P, Valnot I, Barrientos A, Gorbatyuk M, Tzagoloff A, Taanman JW, Benayoun E, Chrétien D, Kadhom N, Lombès A, et al: A mutant mitochondrial respiratory chain assembly protein causes complex III deficiency in patients with tubulopathy, encephalopathy and liver failure. Nat Genet 29: 57-60, 2001.

69. Magner M, Dvorakova V, Tesarova M, Mazurova S, Hansikova H, Zahorec M, Brennerova K, Bzduch V, Spiegel R, Horovitz Y, et al: TMEM70 deficiency: Long-term outcome of 48 patients. J Inherit Metab Dis 38: 417-426, 2015.
70. Riley LG, Rudinger-Thirion J, Schmitz-Abe K, Thorburn DR, Davis RL, Teo J, Arbuckle S, Cooper ST, Campagna DR, Frugier M, et al: LARS2 Variants Associated with Hydrops, Lactic Acidosis, Sideroblastic Anemia, and Multisystem Failure. JIMD Rep 28: 49-57, 2016.

71. Saada A, Shaag A, Arnon S, Dolfin T, Miller C, Fuchs-Telem D, Lombes A and Elpeleg O: Antenatal mitochondrial disease caused by mitochondrial ribosomal protein (MRPS22) mutation. J Med Genet 44: 784-786, 2007.

72. Tucker EJ, Wanschers BF, Szklarczyk R, Mountford HS, Wijeyeratne XW, van den Brand MA, Leenders AM, Rodenburg RJ, Reljić B, Compton AG, et al: Mutations in the UQCC1-interacting protein, UQCC2, cause human complex III deficiency associated with perturbed cytochrome $\mathrm{b}$ protein expression. PLoS Genet 9: e1004034, 2013.

73. Gupta A, Colmenero I, Ragge NK, Blakely EL, He L, McFarland R, Taylor RW, Vogt J and Milford DV: Compound heterozygous RMND1 gene variants associated with chronic kidney disease, dilated cardiomyopathy and neurological involvement: A case report. BMC Res Notes 9: 325, 2016.

74. D'Aco KE, Manno M, Clarke C, Ganesh J, Meyers KE and Sondheimer N: Mitochondrial tRNA(Phe) mutation as a cause of end-stage renal disease in childhood. Pediatr Nephrol 28: $515-519,2013$.

75. Scaglia F, Vogel H, Hawkins EP, Vladutiu GD, Liu LL and Wong LJ: Novel homoplasmic mutation in the mitochondrial tRNATyr gene associated with atypical mitochondrial cytopathy presenting with focal segmental glomerulosclerosis. Am J Med Genet A 123A: 172-178, 2003.

76. Matsumura M, Nakashima A, Araki T, Tofuku Y, Koizumi J, Yagi K, Koni I and Mabuchi H: L-Carnitine supplementation in a hemodialysis patient with a mutation in the mitochondrial tRNA(Leu(UUR)) gene. Nephron 85: 275-276, 2000

77. Ashraf S, Gee HY, Woerner S, Xie LX, Vega-Warner V, Lovric S, Fang H, Song X, Cattran DC, Avila-Casado C, et al: ADCK4 mutations promote steroid-resistant nephrotic syndrome through CoQ10 biosynthesis disruption. J Clin Invest 123: 5179-5189, 2013.

78. McDonald DG, McMenamin JB, Farrell MA, Droogan O and Green AJ: Familial childhood onset neuropathy and cirrhosis with the $4977 \mathrm{bp}$ mitochondrial DNA deletion. Am J Med Genet 111: 191-194, 2002.

79. Broomfield A, Sweeney MG, Woodward CE, Fratter C, Morris AM, Leonard JV, Abulhoul L, Grunewald S, Clayton PT, Hanna MG, et al: Paediatric single mitochondrial DNA deletion disorders: An overlapping spectrum of disease. J Inherit Metab Dis 38: 445-457, 2015

80. Capková M, Tesarová M, Wenchich L, Cerná L, Hansíková H, Hůlková H, Hrubá E, Elleder M and Zeman J: Disorders of mitochondrial energy metabolism in patients with the Kearns-Sayre syndrome. Cas Lek Cesk 141: 51-54, 2002 (In Czech).

81. Löwik MM, Hol FA, Steenbergen EJ, Wetzels JF and van den Heuvel LP: Mitochondrial tRNALeu(UUR) mutation in a patient with steroid-resistant nephrotic syndrome and focal segmental glomerulosclerosis. Nephrol Dial Transplant 20: 336-341, 2005.

82. Tzen CY, Tsai JD, Wu TY, Chen BF, Chen ML, Lin SP and Chen SC: Tubulointerstitial nephritis associated with a novel mitochondrial point mutation. Kidney Int 59: 846-854, 2001.

83. Tabebi M,Mkaouar-Rebai E, Mnif M,KallabiF,Ben Mahmoud A, Ben Saad W, Charfi N, Keskes-Ammar L, Kamoun H, Abid M, et al: A novel mutation MT-COIII m.9267G $>\mathrm{C}$ and MT-COI m.5913G $>$ A mutation in mitochondrial genes in a Tunisian family with maternally inherited diabetes and deafness (MIDD) associated with severe nephropathy. Biochem Biophys Res Commun 459: 353-360, 2015.

84. Bourdon A, Minai L, Serre V, Jais JP, Sarzi E, Aubert S, Chrétien D, de Lonlay P, Paquis-Flucklinger V, Arakawa H, et al: Mutation of RRM2B, encoding p53-controlled ribonucleotide reductase (p53R2), causes severe mitochondrial DNA depletion. Nat Genet 39: 776-780, 2007.

85. Kanabus M, Shahni R, Saldanha JW, Murphy E, Plagnol V, Hoff WV, Heales S and Rahman S: Bi-allelic CLPB mutations cause cataract, renal cysts, nephrocalcinosis and 3-methylglutaconic aciduria, a novel disorder of mitochondrial protein disaggregation. J Inherit Metab Dis 38: 211-219, 2015.

86. Distelmaier F, Haack TB, Catarino CB, Gallenmüller C Rodenburg RJ, Strom TM, Baertling F, Meitinger T, Mayatepek E, Prokisch $\mathrm{H}$, et al: MRPL44 mutations cause a slowly progressive multisystem disease with childhood-onset hypertrophic cardiomyopathy. Neurogenetics 16: 319-323, 2015. 